\title{
Cost-effectiveness evaluation of escitalopram in major depressive disorder in Italy
}

This article was published in the following Dove Press journal:

ClinicoEconomics and Outcomes Research

5 February 2013

Number of times this article has been viewed

\section{Claudio Mencacci' \\ Guido Di Sciascioº \\ Pablo Katz ${ }^{3}$ \\ Claudio Ripellino ${ }^{3}$ \\ 'Ospedale Fatebenefratelli, Milan, Italy; ${ }^{2}$ Azienda Ospedaliera Universitaria Consorziale Policlinico di Bari, Bari, Italy; ${ }^{3}$ CSD Medical Research Srl, Milan, Italy}

Correspondence: Pablo Katz

Viale E. Jenner, 53 - 20159 Milano, Italy

Tel +3902 69770335

Fax +3902 690I 0325

Email pablo.katz@cegedim.com
Background: Depression has a lifetime prevalence of $10 \%-25 \%$ among women and $5 \%-12 \%$ among men. Selective serotonin reuptake inhibitors (SSRIs) are the most used and the most cost-effective treatment for long-term major depressive disorder. Since the introduction of generic SSRIs, the costs of branded drugs have been questioned. The objective of this study was to assess the cost-effectiveness ( $€$ per quality-adjusted life year [QALY]) of escitalopram (which is still covered by a patent) compared with paroxetine, sertraline, and citalopram, the patents for which have expired.

Methods: A decision analytic model was adapted from the Swedish Dental and Pharmaceutical Benefits agency model to reflect current clinical practice in the treatment of depression in Italy in collaboration with an expert panel of Italian psychiatrists and health economists. The population comprised patients with a first diagnosis of major depressive disorder and receiving for the first time one of the following SSRIs: escitalopram, sertraline, paroxetine, and citalopram. The time frame used was 12 months. Efficacy and utility data for the original model were validated by our expert panel. Local data were considered for resource utilization and for treatment costs based on the Lombardy region health service perspective. Several scenario simulations, oneway sensitivity analyses, and Monte Carlo simulations were performed to test the robustness of the model.

Results: The base case scenario showed that escitalopram had an incremental cost-effectiveness ratio (ICER) of $€ 4395$ and $€ 1080$ per QALY compared with sertraline and paroxetine, respectively. Escitalopram was dominant over citalopram, which was confirmed by most one-way sensitivity analyses. The escitalopram strategy gained 0.011 QALYs more than citalopram, 0.008 more than paroxetine, and around 0.007 more than sertraline. Monte Carlo simulations indicated that ICER values for escitalopram were centered around $€ 1100$ and $€ 4400$ per QALY compared with paroxetine and sertraline, respectively. Although there is no official cost-effectiveness threshold in Italy, the value of $€ 25,000$ per QALY could be acceptable. All ICER values retrieved in all analyses were lower than this threshold.

Conclusion: The findings from this cost-effectiveness analysis indicate that escitalopram could be accepted as a cost-effective strategy for the Lombardy region health service compared with the other SSRIs studied. The present assessment is based on ICER values resulting from this analysis, which are lower than the thresholds proposed by health care authorities in other European Union countries. These benefits are driven by the effectiveness of escitalopram, which result in an improved health-related quality of life, a higher probability of sustained remission, and better utilization of health care resources. The study results are robust and in line with other pharmacoeconomic analyses comparing escitalopram with other SSRIs.

Keywords: CEA, depression, escitalopram, Lombardy, ICER, SSRI 


\section{Introduction}

Depression is a severe and pervasive disorder and a chronic recurrent illness associated with significant disability, impaired health-related quality of life, and increased mortality, and is at least as debilitating as other chronic conditions, such as diabetes mellitus and heart disease. ${ }^{1}$ Depression has an estimated lifetime prevalence of $10 \%-25 \%$ in women and $5 \%-12 \%$ in men. ${ }^{2}$ In Italy, the overall prevalence is around $3 \% .^{3}$ Major depressive disorder is a persistent debilitating mental disorder that affects around 120 million adults worldwide, ${ }^{4}$ and in Italy, the number of people with major depressive disorder is estimated to be about 5 million, with a lifelong prevalence of between $8 \%$ and $13 \%$.

Major depressive disorder represents a substantial burden not only in terms of direct costs (eg, treatments, hospitalizations), ${ }^{5}$ which represent $24 \%$ of the total costs, and are paid by patients, their families, and the health services, but also for the indirect and intangible costs (decreased productivity, comorbidities, early retirement, or death), which account for $62 \%$ of the overall costs of depression and impact on society and economic productivity. ${ }^{6,7}$ Kind and Sorensen have shown that pharmacological treatments accounted for $11.3 \%$ of the total (direct, indirect, and intangible) costs of major depressive disorder. ${ }^{8}$ The economic burden of this disease was estimated at USD 83.1 billion worldwide in 2004. Approximately $60 \%$ of patients affected by major depressive disorder never seek treatment, whereas those who do seek help are likely to be undertreated. ${ }^{9}$ Major depressive disorder is associated with an increased risk of relapse after a first episode and a high risk of suicidal behavior.

The main therapeutic modalities for major depressive disorder include antidepressant medication, psychotherapy, and somatic treatment. Selective serotonin reuptake inhibitors (SSRIs) and serotonin-norepinephrine reuptake inhibitors are two effective classes of antidepressants with a better safety profile in comparison with the traditional agents, such as the tricyclic antidepressants. ${ }^{10}$ SSRIs are also more cost-effective in long-term treatment than the older antidepressants in major depressive disorder. ${ }^{10,11}$ Although pharmacological, psychological, and case management interventions are all recommended, antidepressant drugs remain the mainstay of treatment for depression for most people in contact with health care services. ${ }^{12,13}$

The first generic SSRI appeared in 2001 with fluoxetine. Since then most SSRIs have lost their patent protection. Currently, escitalopram is the only SSRI covered by a patent. A recent literature review by Ciprani et al identified clinically important differences among commonly prescribed antidepressants, in terms of both efficacy and acceptability, in favor of escitalopram and sertraline. In particular, this metaanalysis showed that mirtazapine, escitalopram, venlafaxine, and sertraline were more effective, in terms of response, than duloxetine, fluoxetine, fluvoxamine, paroxetine, and reboxetine. In terms of acceptability, escitalopram, sertraline, citalopram, and bupropion were better than other secondgeneration antidepressants. ${ }^{14}$

Since the introduction of generic SSRIs, the higher costs of the branded drugs have been questioned. Furthermore, health services stakeholders need pharmacoeconomic data to be able to make decisions about where resources should be allocated. The Italian National Health Service was instituted in 1978 to provide universal health care for its citizens; it is organized under the Ministry of Health and is administered on a regional basis.

Nevertheless, there are large and growing differences in regional health service organization and provision. Covered are inpatient treatments that include tests and medications, as well as surgeries during hospitalization, family doctor visits, medical assistance provided by pediatricians, and other specialists. The health service also shoulders the costs of drugs, outpatient treatment, and dental treatment.

The 1978 reform law inaugurated fundamental changes in the mental health care system, prohibiting admissions to state mental hospitals, stipulating community-based services and allowing hospitalization only in small general hospital units. The Lombardy mental health system is strongly based on community care. There is a comprehensive network of inpatient and outpatient, residential, and semiresidential facilities.

The objective of this study was to assess the costeffectiveness of escitalopram versus generic paroxetine, sertraline, and citalopram in the treatment of major depressive disorder, adopting the Lombardy region health service perspective, and identifying major cost drivers. The drugs included in this analysis were chosen because they are the most widely prescribed SSRI antidepressants in Italy. ${ }^{15}$

\section{Materials and methods Description of model}

A decision analytic model was developed to simulate the management of Italian patients with major depressive disorder over a time horizon of 12 months by combining clinical outcomes with resource utilization. The starting point was a pharmacoeconomic model developed by the Swedish Dental and Pharmaceutical Benefits agency (TLV). ${ }^{16}$ The 12-month time frame used for the economic evaluation of antidepressants was chosen to include the largest proportion 
of clinical events within a given depressive episode. However, the time frame should not be so long that extrapolations beyond the available clinical and real-life data may jeopardize the accuracy of the model.

An expert panel comprising three psychiatrists under the supervision of two health economists from an independent agency was responsible for evaluating the original model and for adapting it to Italian clinical practice and context.

Unlike the original model, which evaluated the costeffectiveness of several antidepressant drugs (eg, SSRIs, serotonin-norepinephrine reuptake inhibitors), we evaluated four drugs of the SSRIs class, ie, escitalopram, citalopram, paroxetine, and sertraline, because these four antidepressants represent the most prescribed SSRIs in Italy. In contrast to the TLV model in which, after initial treatment failure, patients switched therapy to venlafaxine and/or passed to specialist care (combination of the third and fourth step from STAR *D), ${ }^{17}$ our model considered each treatment line, from the first to the fourth, separately, following the STAR*D study. Efficacy data were retrieved from the TLV model. Utility data from the original model were assessed by our expert panel. Local data were considered for resource utilization and for treatment costs based on the Lombardy regional health service perspective. The decision tree was developed using TreeAge Pro 2011 software (TreeAge Software Inc, Williamstown, MA, USA) and its structure is presented in Figure 1.

The population involved in this pharmacoeconomic analysis comprised patients with a first diagnosis of major depressive disorder and receiving for the first time one of the following SSRIs: escitalopram, sertraline, paroxetine, and citalopram. The treatment objectives were to achieve remission, measured by a score of $\leq 7$ on the Hamilton Depression Rating scale. We assumed that patients achieving remission in the first treatment step in the model would do so after one month of treatment. ${ }^{16}$

Once in remission, if the patient does not relapse, defined as a new major depressive disorder episode occurring within 6 months after remission, then she/he was treated with a maintenance treatment for 6 months in accordance with the international treatment guidelines; otherwise if the patient relapsed, it was assumed that relapse occurs after 4 months of starting treatment. Patients who failed to respond, defined as not achieving remission in the first treatment line, move to a second-line therapy. A proportion of these patients might attempt suicide. Those patients who achieve remission in the second line of treatment, which we have assumed to occur after one month, receive maintenance treatment for 6 months, whereas those who do not achieve remission at the second line of treatment move to the third line of treatment. Patients move to the third and fourth treatment lines according to the same criteria described for second-line treatment.

\section{Model parameters Efficacy}

The remission probabilities for the first line of treatment were derived from an independent meta-analysis made by the TLV as specified in Table 1. Several studies were included in this

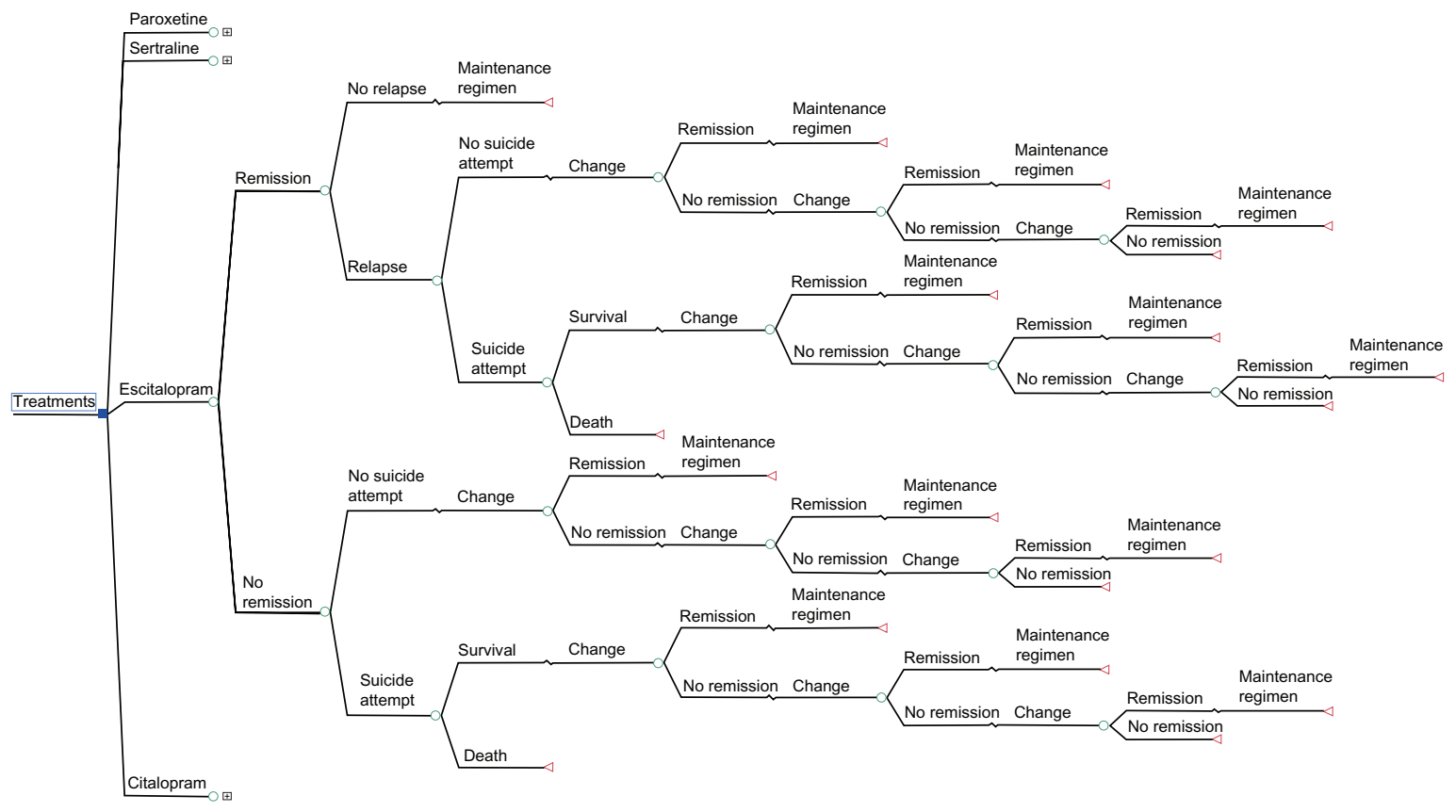

Figure I Decision analytic model. 
Table I Treatment strategies and lines, and drug remission probabilities

\begin{tabular}{|c|c|c|c|c|}
\hline \multirow[t]{2}{*}{ Treatments } & \multirow{2}{*}{$\begin{array}{l}\text { Remission } \\
\text { probabilities }\end{array}$} & \multicolumn{2}{|c|}{ Sensitivity analisys } & \multirow[t]{2}{*}{ Source } \\
\hline & & MIN -5\% & $\operatorname{MAX}+5 \%$ & \\
\hline \multicolumn{5}{|l|}{ Initial treatment } \\
\hline Initial treatment - escitalopram & 0.476 & 0.452 & 0.499 & Wessling and Ramsberg ${ }^{16}$ \\
\hline Initial treatment - citalopram & 0.405 & & & Wessling and Ramsberg ${ }^{16}$ \\
\hline Initial treatment - sertraline & 0.430 & & & Wessling and Ramsberg ${ }^{16}$ \\
\hline Initial treatment - paroxetine & 0.427 & & & Wessling and Ramsberg ${ }^{16}$ \\
\hline \multicolumn{5}{|l|}{ 2nd-line treatment } \\
\hline \multicolumn{5}{|l|}{ Switch } \\
\hline SNRI (venlafaxine RP) & 0.250 & & & Gaynes et al ${ }^{17}$ \\
\hline Tryclicic (amitriptiline) & 0.257 & & & Adapted from TLV model ${ }^{16}$ \\
\hline Other SSRI (sertraline, escitalopram, citalopram, paroxetine) & 0.266 & & & Adapted from STAR*D ${ }^{17}$ \\
\hline \multicolumn{5}{|l|}{ Combination } \\
\hline Tryciclic (amitriptiline) + initial treatment & 0.395 & & & Adapted from TLV model ${ }^{16}$ \\
\hline SNRI (venlafaxine RP) + initial treatment & 0.395 & & & Adapted from TLV model ${ }^{16}$ \\
\hline NARI (reboxetine) + initial treatment & 0.395 & & & Adapted from TLV model ${ }^{16}$ \\
\hline TECA (mirtazapine) + initial treatment & 0.395 & & & Adapted from TLV model ${ }^{16}$ \\
\hline Total 2th-line treatment & 0.336 & 0.319 & 0.353 & \\
\hline \multicolumn{5}{|l|}{ 3rd-line treatment } \\
\hline \multicolumn{5}{|l|}{ Augmentation } \\
\hline Lithium + 2nd-line & 0.145 & & & Gaynes et al ${ }^{17}$ \\
\hline Thyroids $(T 3)+2$ nd-line & 0.257 & & & Gaynes et $\mathrm{l}^{17}$ \\
\hline Antipsychotics atypical (quetiapine) $+2 n d-$ line & 0.361 & & & Nelson and Papakostas ${ }^{37}$ \\
\hline Total 3th-line treatment & 0.254 & 0.242 & 0.267 & \\
\hline \multicolumn{5}{|l|}{ 4th-line treatment } \\
\hline \multicolumn{5}{|l|}{ Switch } \\
\hline I-MAO (Tranylcypromine) & 0.145 & & & Gaynes et $\mathrm{al}^{17}$ \\
\hline Total 4th-line treatment & 0.145 & 0.13775 & 0.15225 & \\
\hline
\end{tabular}

meta-analysis for a total of about 20,000 patients, ${ }^{16}$ and in order to exclude potential bias related to level of sponsorship of the articles, the authors applied adjustments in the meta-analysis.

The mixed treatment comparison statistical method was used to compare more than two treatments that were not part of the same direct head-to-head study. This approach made it possible to estimate the effect of all relevant treatments and combine all the information from the relevant studies. The study had to report remission as $\leq 7$ or 8 Hamilton Depression Rating scale points or as $\leq 12$ Montgomery-Åsberg Depression Rating Scale points. Therefore, the expert panel considered this meta-analysis robust enough for the aim of our pharmacoeconomic study.

Our scientific expert panel analyzed and adapted second, third, and fourth treatment strategies and lines described in the STAR*D study, ${ }^{17}$ considered as the reference study, to Italian standard clinical practice.

After failure of initial treatment, patients move to a second-line treatment consisting of a switching strategy or a combination strategy; if the second-line treatment failed, the patients passed to a third treatment line consisting of an augmentation strategy and, finally, if this last strategy failed, the patients passed to a fourth line consisting of a switching strategy carried out during hospitalization (for details on drugs see Table 1). We assumed that patients had the same probability of receiving one of the different treatments within each treatment line.

Second, third, and fourth treatment line remission probabilities were discussed with the expert panel, which agreed to adapt $\mathrm{STAR} * \mathrm{D}$ remission probabilities to the treatments that are not present in the STAR*D study, but are the ones usually used in normal Italian clinical practice. For these treatments, remission probabilities were calculated using the mean probability of remission of the drug classes considered in the STAR*D study. Regarding the probability of relapse, a systematic review of two observational studies in primary care was performed. ${ }^{18}$ In these studies, the relapse frequencies were $11 \%$ and $30 \%$, respectively; however, the latter study was very small. The STAR*D study had a $33.5 \%$ relapse rate for those patients who achieved remission in the first step. Patients who suffered a relapse experienced this condition at an average of 4.4 months after remission. In our 
main analysis, we assumed the risk of relapse to be $11 \%$ and that relapse occurs after 4 months. ${ }^{18}$ For suicide attempts and the probability of dying, we followed Löthgren and Khan, setting the risk of suicide attempts at 0.031 and the risk of dying in such an attempt at 0.1 (Table 2). ${ }^{19,20}$

\section{Drug costs}

Monthly drug costs were calculated by multiplying, for each presentation, unit costs in milligrams by daily dose and by 30 days of usage (Table 3). A mean of the costs of all the available commercial presentations was used to define the monthly costs for the different antidepressants (Table 4).

Unit costs in milligrams were calculated by dividing the price of the commercial presentation by the total strength in each box (mg). For the generic drugs, we considered the price reimbursed by the regional health service while for the branded drugs we considered the public price. In both cases, $€ 2$ of copayment (ticket) for each drug prescription directly paid by the patient was subtracted from the respective prices. The data source was the Italian Drug Agency website. ${ }^{21}$

Regarding drug dosages, we used the defined daily dosages retrieved from the website of the World Health Organization Collaborative Center for Drug Statistics Methodology which, according to our expert panel, fits well with standard clinical practice in Italy. ${ }^{22}$ A sensitivity analysis was performed using the mean daily doses derived from the Summary of Product Characteristics and the results are shown in the Results section.

\section{Resource utilization}

This analysis considered direct medical costs including those of general practitioner visits, specialist visits, patient examinations, and hospitalizations. Considering the perspective of the model, which is that of the Lombardy region health service, the costs were those directly reimbursed by the regional health service. Indirect costs have not been evaluated in this model due to perspective and data availabilities (no accurate data in Lombardy).

Resource utilization was assessed by our expert panel to reflect standard clinical practice in Italy. They advised a list of examinations that, according to standard clinical

Table 2 Probabilities

\begin{tabular}{lll}
\hline Parameter & Value & Reference \\
\hline Probability of relapse & 0.11 & Gilchrist and Gunn ${ }^{18}$ \\
Probability of attempted suicide & 0.03 & Lothgren et al ${ }^{19}$ \\
Probability of death due to attempted & 0.10 & Lothgren et al $^{19}$ \\
suicide & & \\
\hline
\end{tabular}

Table 3 Drug dosages

\begin{tabular}{lll}
\hline Active principal & $\begin{array}{l}\text { Defined daily } \\
\text { dose }(\mathbf{m g})\end{array}$ & $\begin{array}{l}\text { Mean daily dose } \\
(\mathbf{m g}) \text { (from SPC) }\end{array}$ \\
\hline Citalopram & 20 & 40 \\
Paroxetine & 20 & 40 \\
Sertraline & 50 & 125 \\
Escitalopram & 10 & 15 \\
Venlafaxine XR & 100 & 150 \\
Mirtazapine & 30 & 30 \\
Lithium & 900 & 1200 \\
Amitryptiline & 75 & 137.5 \\
Reboxetine & 8 & 10 \\
Thyroid T3 $(\mu \mathrm{g})$ & 150 & 50 \\
Quetiapine & 400 & 300 \\
\hline Ab &
\end{tabular}

Abbreviation: SPC, summary of product characteristics.

practice, are prescribed at first visits and estimated as an annual mean number of general practitioners and specialist visits (Table 5). From this last assessment, we decided to allocate all examinations to the first month and to distribute homogeneously the visits in each patient pathway indistinctly over the 12-month time horizon. Unit costs, expressed in $€$, were retrieved from 2011 Lombardy region official prices and diagnosis-related group pricelists, and were applied to the resource utilization data (Table 5).

\section{Utilities}

In health economics, utilities are cardinal values that reflect an individual's preferences for different health outcomes. They are measured on an interval scale, with 0 reflecting a state of health equivalent to death and 1 reflecting perfect health. Utilities are typically combined with survival estimates and aggregated across individuals to generate quality-adjusted life years (QALYs) for use in cost-effectiveness analyses of

Table 4 Drug costs $(€)$

\begin{tabular}{llll}
\hline Active principle & $\begin{array}{l}\text { MG } \\
\text { price }\end{array}$ & $\begin{array}{l}\text { Monthly cost } \\
\text { (with DDD) }\end{array}$ & $\begin{array}{l}\text { Monthly cost } \\
\text { (MDD from SPC) }\end{array}$ \\
\hline Citalopram & 0.012 & 7.5 & 15.0 \\
Paroxetine & 0.017 & 10.3 & 20.7 \\
Sertraline & 0.004 & 6.6 & 16.4 \\
Escitalopram & 0.081 & 24.3 & 36.4 \\
ALL SSRls & & 12.2 & 22.1 \\
Venlafaxine XR & 0.005 & 16.0 & 24.0 \\
Mirtazapine & 0.016 & 14.7 & 14.7 \\
Lithium & 0.000 & 1.3 & 1.7 \\
Amitriptiline & 0.001 & 3.2 & 6.0 \\
Reboxetine & 0.098 & 23.5 & 29.4 \\
Thyroids T3 (mcg) & 0.001 & 3.9 & 1.3 \\
Tranilcipramine & 0.000 & 0.0 & 0.0 \\
Quetiapine & 0.014 & 170.1 & 127.6 \\
\hline Abbrevitions DDD & defned
\end{tabular}

Abbreviations: DDD, defined daily dose; MDD, mean daily dose; SPC, summary of product characteristic; SSRls, selective serotonin reuptake inhibitors; T3, triiodothyronine; XR, extended release. 
Table 5 Resource utilization and costs

\begin{tabular}{|c|c|c|}
\hline Parameter & Value & Source \\
\hline \multicolumn{3}{|l|}{ Visits } \\
\hline $\begin{array}{l}\text { Annual mean number } \\
\text { of specialist visits }\end{array}$ & 13.7 & Expert opinion \\
\hline $\begin{array}{l}\text { Annual mean number } \\
\text { of GP visits }\end{array}$ & 7.5 & Expert opinion \\
\hline $\begin{array}{l}\text { Cost of first specialist } \\
\text { visit }(€)\end{array}$ & 22.5 & $\begin{array}{l}\text { Lombardy } 2011 \\
\text { examinations price list }\end{array}$ \\
\hline $\begin{array}{l}\text { Cost of following } \\
\text { specialist visit }\end{array}$ & 17.5 & $\begin{array}{l}\text { Lombardy } 201 \mathrm{I} \\
\text { examinations price list }\end{array}$ \\
\hline Cost of GP visits $(€)$ & 12.0 & Garattini et $\mathrm{al}^{38}$ \\
\hline \multicolumn{3}{|l|}{ Examinations } \\
\hline $\begin{array}{l}\text { Annual mean number } \\
\text { of electrocardiograms }\end{array}$ & 1.0 & Expert opinion \\
\hline $\begin{array}{l}\text { Annual mean number } \\
\text { of thyroid exams }\end{array}$ & 1.0 & Expert opinion \\
\hline $\begin{array}{l}\text { Annual mean number } \\
\text { of hematochemical exams }\end{array}$ & 1.0 & Expert opinion \\
\hline $\begin{array}{l}\text { Annual mean number } \\
\text { of CAT }\end{array}$ & 0.5 & Expert opinion \\
\hline $\begin{array}{l}\text { Annual mean number } \\
\text { of electroencephalograms }\end{array}$ & 1.0 & Expert opinion \\
\hline Cost of electrocardiogram $(€)$ & 11.6 & $\begin{array}{l}\text { Lombardy } 201 \mathrm{I} \\
\text { examinations price list }\end{array}$ \\
\hline Cost of thyroid exams $(€)$ & 27.4 & $\begin{array}{l}\text { Lombardy } 201 \mathrm{I} \\
\text { examinations price list }\end{array}$ \\
\hline $\begin{array}{l}\text { Cost of hematochemical } \\
\text { exams }(€)\end{array}$ & 29.1 & $\begin{array}{l}\text { Lombardy } 201 \mathrm{I} \\
\text { examinations price list }\end{array}$ \\
\hline Cost of CAT $(€)$ & 99.2 & $\begin{array}{l}\text { Lombardy } 201 \mathrm{I} \\
\text { examinations price list }\end{array}$ \\
\hline $\begin{array}{l}\text { Cost of } \\
\text { electroencephalograms }(€)\end{array}$ & 23.8 & $\begin{array}{l}\text { Lombardy } 201 \mathrm{I} \\
\text { examinations price list }\end{array}$ \\
\hline \multicolumn{3}{|l|}{ Hospitalizations } \\
\hline $\begin{array}{l}\text { Hospitalization with } \\
\text { attempted suicide }\end{array}$ & 3785.0 & $\begin{array}{l}\text { Lombardy 20II DRG } \\
\text { price list }\end{array}$ \\
\hline $\begin{array}{l}\text { Hospitalization without } \\
\text { attempted suicide }\end{array}$ & 2619.5 & $\begin{array}{l}\text { Lombardy 20II DRG } \\
\text { price list }\end{array}$ \\
\hline
\end{tabular}

Note: Expert opinion was that of a panel comprising three psychiatrists under the supervision of two health economists from an independent agency.

Abbreviations: DRG, diagnosis related groups; GP, general practitioner; CAT, computed axial tomography.

health care interventions. The treatment effects have been expressed as QALYs with the aid of data from Sobocki et al, ${ }^{23}$ where utilities for a patient who achieves remission and for one who does not are calculated as 0.81 and 0.57 , respectively. The TLV model considered the utility for patients in relapse and the utility for patients who attempt suicide to be equal to patients who do not achieve remission. ${ }^{16}$ Our expert panel did not validate this approach because, according to their clinical experience, patients who relapse have a higher quality of life than patients not in remission, because they experience remission at least once and patients who attempt suicide have a lower quality of life than patients not in remission, because they have a higher score on the Hamilton Rating Scale for Depression. ${ }^{24}$ Furthermore, a literature review showed a lack of information regarding utility values for patients who relapse and for patients who attempt suicide. As a consequence, the authors decided to perform an analysis based on the utility values suggested by the expert panel (Table 6) and to test the results by performing another analysis using the original data from Sobocki et al and to compare the results of the two cost-effectiveness analyses. ${ }^{23}$

\section{Analyses}

Cost-effectiveness analysis is a method for assessing gains in health relative to the costs of different health interventions. It is not the only criterion for deciding how to allocate resources, but it is an important one because it directly relates the financial and scientific implications of different interventions. One type of cost-effectiveness analysis is cost-utility analysis, in which the basic calculation involves dividing the cost of an intervention in monetary units by the expected health gain measured in QALYs. ${ }^{25}$ Nevertheless, in this study, we will speak generally about cost-effectiveness analysis.

The main outcome of the cost-effectiveness analysis is the incremental cost effectiveness ratio (ICER). The ICER represents the difference in costs divided by the difference in outcomes observed between two alternative programs. It represents the additional cost due to a new technology related to its additional benefits.

$$
\operatorname{ICER}=\frac{\Delta C}{\Delta E}=\frac{C_{1}-C_{0}}{E_{1}-E_{0}}
$$

where $\Delta \mathrm{C}$ is the difference in total cost between intervention 1 and intervention 0 , and $\Delta \mathrm{E}$ is the difference in effectiveness between intervention 1 and intervention 0 .

The ICER has to be compared with a meaningful threshold value and many agencies have studied this threshold. The most recognized agency is the National Institute for Health and Clinical Excellence in the UK that proposes a threshold of $€ 35,000$ per QALY. ${ }^{26}$ In Italy, there is no official

Table 6 Utilities

\begin{tabular}{lll}
\hline Parameter & Value & Source \\
\hline $\begin{array}{l}\text { Utility of patient } \\
\text { in remission }\end{array}$ & 0.847 & $\begin{array}{l}\text { Expert opinion (KOL) } \\
\text { based on Sobocki et al }{ }^{23}\end{array}$ \\
$\begin{array}{l}\text { Utility of patient not } \\
\text { in remission }\end{array}$ & 0.490 & $\begin{array}{l}\text { Expert opinion (KOL) } \\
\text { based on Sobocki et al }{ }^{23}\end{array}$ \\
$\begin{array}{l}\text { Utility of patient in relapse } \\
\text { Utility of patient who }\end{array}$ & 0.550 & $\begin{array}{l}\text { Expert opinion } \\
\text { attempts suicide }\end{array}$ \\
\hline
\end{tabular}

Note: Expert opinion was that a of panel comprising three psychiatrists under the supervision of two health economists from an independent agency.

Abbreviation: KOL, key opinion leader. 
cost-effectiveness threshold, so some authors have proposed to use these latter values for Italy. ${ }^{27}$ Some authors have also proposed to reduce the National Institute for Health and Clinical Excellence threshold for wider use of some more cost-effective treatments. ${ }^{28}$ Based on this paper, we decided to use a threshold of $€ 25,000$ per QALY for this analysis. An ICER value lower than the threshold lets us assume that one technology has a higher probability of being considered costeffective in comparison with the other technology. ${ }^{26,29,30}$

The interpretation of ICER results depends on the level of confidence or uncertainty in various parameters. In this case, it may be necessary to know the likely impact of using alternative values of the parameters and examining the sensitivity of the model to changes in its inputs. The simplest form of sensitivity analysis is to simply vary one value in the model by a given amount, and examine the impact that the change has on the model's results. This is known as one-way sensitivity analysis, because only one parameter is changed at one time. In our model, we decided to perform the following one-way sensitivity analyses:

- probability of remission of escitalopram in first line $\pm 5 \%$

- probability of remission of second line $\pm 5 \%$

- probability of remission of third line $\pm 5 \%$

- probability of remission of fourth line $\pm 5 \%$

- probability of relapse equal to 0.335

- mean daily doses values to calculate daily costs

- utility values from Sobocki et $\mathrm{al}^{23}$

Another form of sensitivity analysis is the Monte Carlo simulation, which performs several analyses by building models of possible results and substituting a range of values or a probability distribution for any factor that has inherent uncertainty. It then calculates results many times, each time using a different set of random values from the probability functions. Monte Carlo simulations produce distributions of possible outcome values. ${ }^{31}$

One important output of Monte Carlo simulation is the cost-effectiveness acceptability curve (CEAC), which is a graph presenting the uncertainty within the results of a study. This graph plots the probability that the ICER is favorably cost-effective, ie, has a cost-effectiveness ratio below the Lombardy health service willingness-to-pay threshold..$^{32}$

\section{Results}

\section{Base case scenario analysis}

In the base case scenario (see Table 7), patients treated with escitalopram have a mean expected number of QALYs of 0.735 compared with a mean expected number of QALYs of 0.724 for citalopram and 0.728 for paroxetine and sertraline.
Table 7 Results: base case scenario

\begin{tabular}{llll}
\hline Drug & Cost, $€$ & QALY & ICER \\
\hline Escitalopram & 1394.2 & 0.735 & \\
Citalopram & 1401.0 & 0.724 & \\
$\quad$ Difference vs escitalopram & -6.8 & 0.011 & Dominated \\
Paroxetine & 1385.7 & 0.728 & \\
$\quad$ Difference vs escitalopram & 8.5 & 0.008 & 1080.0 \\
Sertraline & 1362.1 & 0.728 & \\
$\quad$ Difference vs escitalopram & 32.1 & 0.007 & 4395.0 \\
\hline
\end{tabular}

Abbreviations: ICER, incremental cost-effectiveness ratio; QALY, quality-adjusted life year.

The escitalopram strategy gains 0.011 QALYs more than citalopram, 0.008 more than paroxetine, and about 0.007 more than sertraline.

The average costs of the different treatment strategies for the 12 -month time frame range from $€ 1362$ for sertraline to $€ 1401$ for citalopram, $€ 1394$ for escitalopram, and $€ 1385$ for paroxetine. The escitalopram strategy costs $€ 32$ more than sertraline, $€ 8.50$ more than paroxetine, and about $€ 6.80$ less than citalopram.

In this context, citalopram was dominated by escitalopram (citalopram had a higher cost and less effectiveness than escitalopram). Paroxetine and sertraline were less costly, but also less effective than escitalopram. Escitalopram had an ICER of $€ 4395$ and $€ 1080$ per QALY compared with sertraline and paroxetine, respectively.

\section{Sensitivity analyses}

Table 8 shows the results of the sensitivity analyses. By decreasing the probability of remission with escitalopram by $5 \%$, the model showed that the ICER of escitalopram versus sertraline increased to $€ 18,092$, the ICER of escitalopram versus paroxetine increased to $€ 9822$, and the ICER of escitalopram versus citalopram was $€ 3191$ per QALY. By increasing the probability of remission of escitalopram by $5 \%$, the model showed that the ICER of escitalopram versus sertraline decreased to $€ 115$ and that both paroxetine and citalopram were dominated by escitalopram.

The model was slightly sensitive to the probability of remission of the second, third, and fourth lines, using an interval of $\pm 5 \%$, and the results varied by around $€ 300$, $€ 180$, and $€ 20$ for the second, third, and fourth treatment line, respectively, compared with the base scenario. Thus, these parameters did not have an important impact on the model, indicating its robustness.

The sensitivity analysis of the probability of relapse using the value 0.335 from the STAR*D study showed that the ICER of escitalopram versus sertraline varied from $€ 4395$ (base case) to $€ 8065$, the ICER of escitalopram versus 
Table 8 Sensitivity analysis

\begin{tabular}{|c|c|c|c|}
\hline Drug & Cost, $€$ & QALY & ICER \\
\hline \multicolumn{4}{|l|}{ Efficacy escitalopram -5\% } \\
\hline Escitalopram & 1425.0 & 0.732 & \\
\hline Citalopram & $|40| .0$ & 0.724 & \\
\hline Difference vs escitalopram & 24.1 & 0.008 & 3191.4 \\
\hline Paroxetine & I385.7 & 0.728 & \\
\hline Difference vs escitalopram & 39.3 & 0.004 & 9822.1 \\
\hline Sertraline & 1362.1 & 0.728 & \\
\hline Difference vs escitalopram & 63.0 & 0.003 & 18092.4 \\
\hline \multicolumn{4}{|l|}{ Efficacy escitalopram $+5 \%$} \\
\hline Escitalopram & 1363.3 & 0.739 & \\
\hline Citalopram & $140 \mid .0$ & 0.724 & \\
\hline Difference vs escitalopram & -37.6 & 0.015 & Dominated \\
\hline Paroxetine & 1385.7 & 0.728 & \\
\hline Difference vs escitalopram & -22.4 & 0.012 & Dominated \\
\hline Sertraline & 1362.1 & 0.728 & \\
\hline Difference vs escitalopram & 1.3 & 0.011 & 115.5 \\
\hline \multicolumn{4}{|c|}{ Efficacy 2 nd-line treatment $-5 \%$} \\
\hline Escitalopram & $14 \mid 3.3$ & 0.733 & \\
\hline Citalopram & 1422.5 & 0.722 & \\
\hline Difference vs escitalopram & -9.2 & 0.012 & Dominated \\
\hline Paroxetine & 1406.6 & 0.725 & \\
\hline Difference vs escitalopram & 6.7 & 0.008 & 841.2 \\
\hline Sertraline & 1382.9 & 0.726 & \\
\hline Difference vs escitalopram & 30.4 & 0.007 & 4076.6 \\
\hline \multicolumn{4}{|c|}{ Efficacy 2 nd-line treatment $+5 \%$} \\
\hline Escitalopram & |375.| & 0.737 & \\
\hline Citalopram & 1379.4 & 0.726 & \\
\hline Difference vs escitalopram & -4.3 & 0.011 & Dominated \\
\hline Paroxetine & 1364.9 & 0.730 & \\
\hline Difference vs escitalopram & 10.2 & 0.008 & 1329.0 \\
\hline \multicolumn{4}{|c|}{ Efficacy 3 nd-line treatment $-5 \%$} \\
\hline Escitalopram & 1403.4 & 0.734 & \\
\hline Citalopram & $|4| 1.5$ & 0.723 & \\
\hline Difference vs escitalopram & -8.1 & 0.012 & Dominated \\
\hline Paroxetine & 1395.9 & 0.726 & \\
\hline Difference vs escitalopram & 7.5 & 0.008 & 951.2 \\
\hline Sertraline & 1372.2 & 0.727 & \\
\hline Difference vs escitalopram & 31.2 & 0.007 & 4220.6 \\
\hline \multicolumn{4}{|c|}{ Efficacy 3 nd-line treatment $+5 \%$} \\
\hline Escitalopram & 1384.2 & 0.737 & \\
\hline Citalopram & 1389.5 & 0.725 & \\
\hline Difference vs escitalopram & -5.4 & 0.011 & Dominated \\
\hline Paroxetine & 1374.7 & 0.729 & \\
\hline Difference vs escitalopram & 9.4 & 0.008 & 1223.3 \\
\hline Sertraline & 1351.0 & 0.729 & \\
\hline Difference vs escitalopram & 33.1 & 0.007 & 4589.3 \\
\hline \multicolumn{4}{|c|}{ Efficacy $4 n d$-line treatment -5\% } \\
\hline Escitalopram & 1393.9 & 0.735 & \\
\hline Citalopram & 1400.6 & 0.724 & \\
\hline Difference vs escitalopram & -6.7 & 0.011 & Dominated \\
\hline Paroxetine & | 385.4 & 0.727 & \\
\hline Difference vs escitalopram & 8.5 & 0.008 & 1076.8 \\
\hline Sertraline & 1361.7 & 0.728 & \\
\hline Difference vs escitalopram & 32.1 & 0.007 & 4373.6 \\
\hline \multicolumn{4}{|c|}{ Efficacy 4 nd-line treatment $+5 \%$} \\
\hline Escitalopram & 1394.5 & 0.736 & \\
\hline
\end{tabular}

Table 8 (Continued)

\begin{tabular}{|c|c|c|c|}
\hline Drug & Cost, $€$ & QALY & ICER \\
\hline Citalopram & 1401.3 & 0.725 & \\
\hline Difference vs escitalopram & -6.8 & 0.011 & Dominated \\
\hline Paroxetine & 1386.0 & 0.728 & \\
\hline Difference vs escitalopram & 8.4 & 0.008 & 1083.I \\
\hline \multicolumn{4}{|l|}{ Relapse probability 0,335} \\
\hline Escitalopram & 1569.4 & 0.724 & \\
\hline Citalopram & 1549.3 & 0.714 & \\
\hline Difference vs escitalopram & 20.1 & 0.010 & 2096.I \\
\hline Paroxetine & 1542.3 & 0.717 & \\
\hline Difference vs escitalopram & 27.1 & 0.007 & 4104.7 \\
\hline Sertraline & 1519.6 & 0.717 & \\
\hline Difference vs escitalopram & 49.8 & 0.006 & 8065.2 \\
\hline \multicolumn{4}{|l|}{ Using MDD } \\
\hline Escitalopram & 1458.5 & 0.735 & \\
\hline Citalopram & 1438.9 & 0.724 & \\
\hline Difference vs escitalopram & 19.6 & 0.011 & 1725.8 \\
\hline Paroxetine & 1438.7 & 0.728 & \\
\hline Difference vs escitalopram & 19.7 & 0.008 & 2520.0 \\
\hline Sertraline & 1412.7 & 0.728 & \\
\hline Difference vs escitalopram & 45.8 & 0.007 & 6269.1 \\
\hline \multicolumn{4}{|l|}{ Using Sobocki utilities } \\
\hline Escitalopram & 1394.2 & 0.735 & \\
\hline Citalopram & 1401.0 & 0.728 & \\
\hline Difference vs escitalopram & -6.8 & 0.008 & Dominated \\
\hline Paroxetine & 1385.7 & 0.730 & \\
\hline Difference vs escitalopram & 8.5 & 0.005 & 1623.7 \\
\hline Sertraline & 1362.1 & 0.730 & \\
\hline Difference vs escitalopram & 32.1 & 0.005 & 6607.3 \\
\hline
\end{tabular}

Abbreviations: ICER, incremental cost-effectiveness ratio; MDD, major depressive disorder; QALY, quality-adjusted life year.

paroxetine varied from $€ 1080$ (base case) to $€ 4104$, and the ICER of escitalopram versus citalopram was $€ 2096$.

Regarding the dosages, we calculated the daily costs of the study drugs using the mean daily dose (calculated from the range suggested by the Summary of Product Characteristics) instead of the defined daily dosages used in the base case scenario. This showed that the ICER of escitalopram versus sertraline increased from $€ 4395$ (base case) to $€ 6269$, the ICER of escitalopram versus paroxetine increased from $€ 1080$ to $€ 2520$, and the ICER of escitalopram versus citalopram was $€ 1725$. Also, a cost-effectiveness ranking performed using utilities from Sobocki et al gave results that were closer to the base case scenario. ${ }^{23}$ The ICER for escitalopram versus sertraline was $€ 6607$ and the ICER for escitalopram versus paroxetine resulted in savings of $€ 1623$.

\section{Monte Carlo simulation}

The model was assessed using Monte Carlo simulation to account for the multivariate uncertainty inherent in input parameters based on 10,000 bootstraps to test model and parameters. Figure 2 shows the ICER distribution probability 


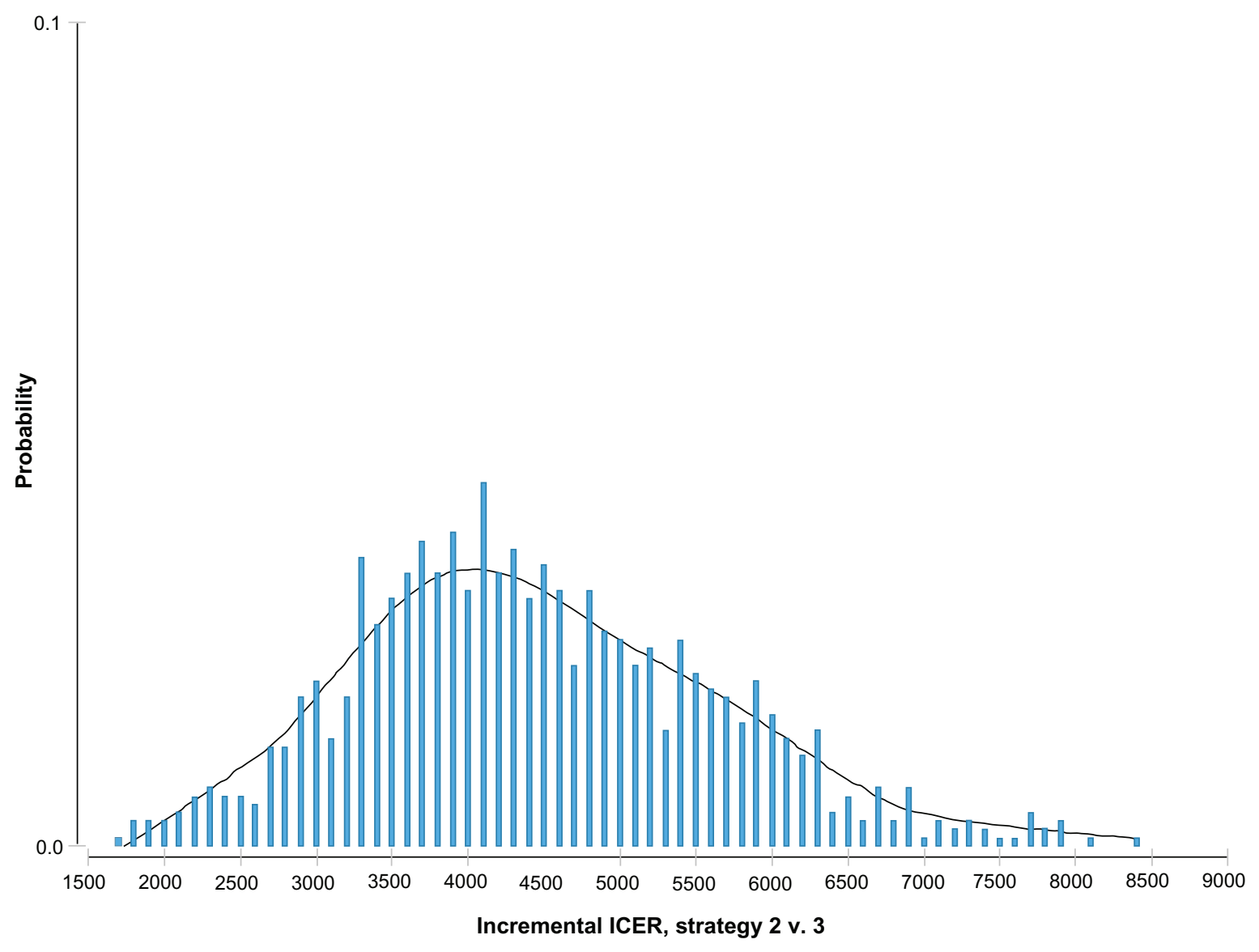

Figure 2 Incremental cost effectiveness ratio (ICER) distribution probability of escitalopram versus sertraline. Note: Mean 4444.2; standard deviation II77.4.

of escitalopram versus sertraline, assuming a normal distribution centered on an average value of $€ 4444$, which was the most probable ICER value for escitalopram versus sertraline.

Figure 3 shows the ICER distribution probability of escitalopram versus citalopram in which the mean of the normal distribution was centered around the negative values $(-€ 561)$. This means that escitalopram dominated citalopram in most simulations. The ICER distribution probability of escitalopram versus paroxetine showed a normal distribution, with an ICER mean value of around $€ 1100$ (Figure 4).

Figure 5 shows strategies for a plan defined in two dimensions, ie, differential cost and differential effectiveness. Citalopram dominated because it had a higher cost and less effectiveness in comparison with escitalopram. Paroxetine and sertraline were in the quadrant for which strategies were less costly and less effective in comparison with escitalopram. Considering a willingness to pay of $€ 25,000$, paroxetine and sertraline were in the part of the plan that is considered sustainable.
The CEAC graph shows how varying the willingness to pay probability impacted the cost-effectiveness probability. The CEAC for escitalopram versus sertraline presented in Figure 6 shows that for a willingness to pay of less than around $€ 5000$, the sertraline strategy had the highest probability of being cost-effective, whereas above $€ 5000$, the most costeffective strategy was escitalopram. A 95\% probability of escitalopram being the most cost-effective was estimated within a willingness to pay that goes from $€ 7000$ to $€ 10,000$.

The CEAC for escitalopram versus paroxetine presented in Figure 7 shows that for a willingness to pay of less than around $€ 1000$, the paroxetine strategy had the highest probability of being cost-effective, whereas above $€ 1000$, the most cost-effective strategy was with escitalopram. Finally, Figure 8 shows the CEAC of escitalopram versus citalopram in which we could see that citalopram, also for a willingness to pay equal to zero, is less cost-effective than escitalopram.

\section{Discussion}

In this cost-effectiveness analysis of escitalopram versus paroxetine, sertraline, and citalopram in major depressive 


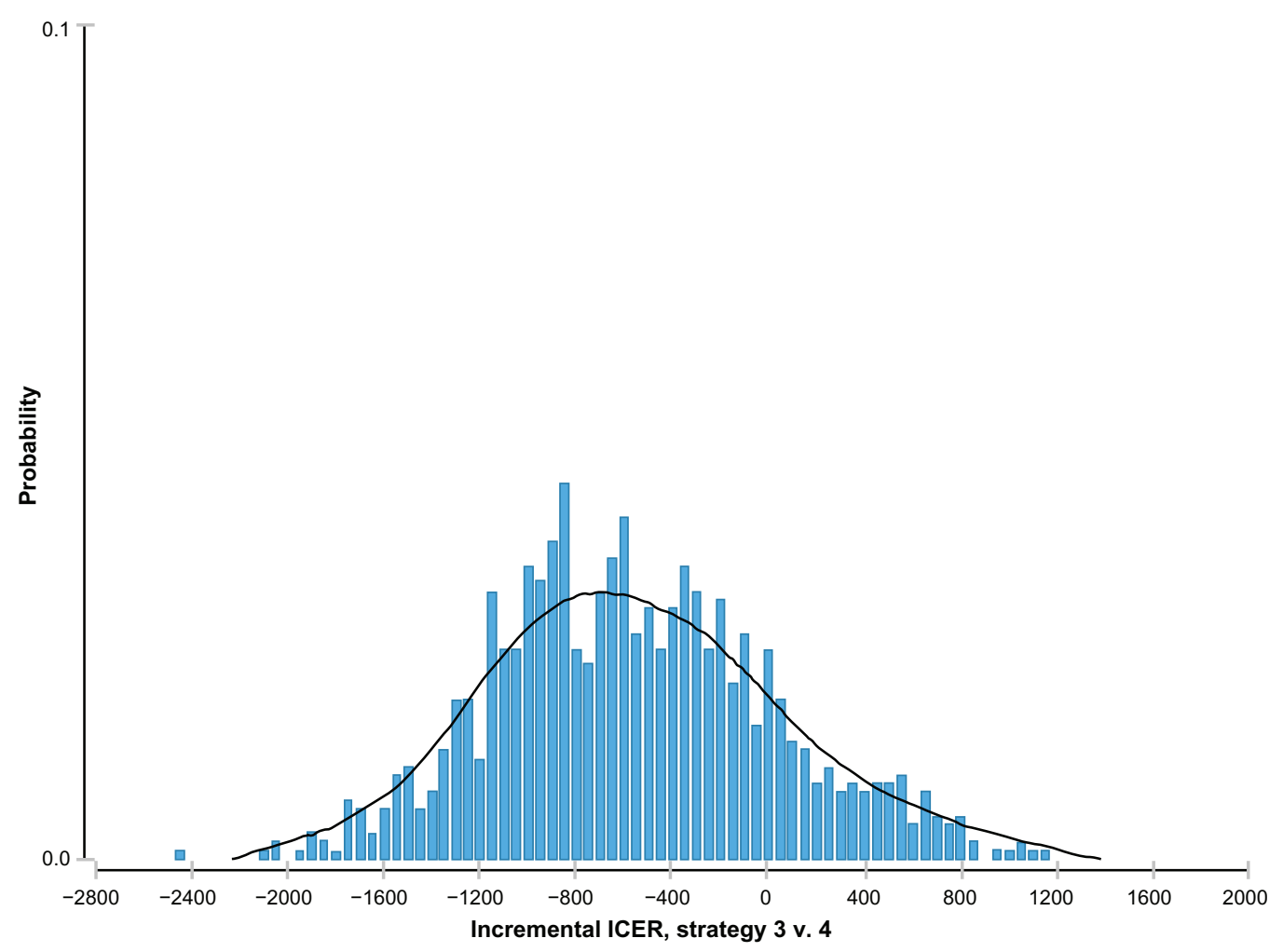

Figure 3 Incremental cost effectiveness ratio (ICER) distribution probability of escitalopram versus citalopram.

Note: Mean -56I.4; standard deviation 589.2.

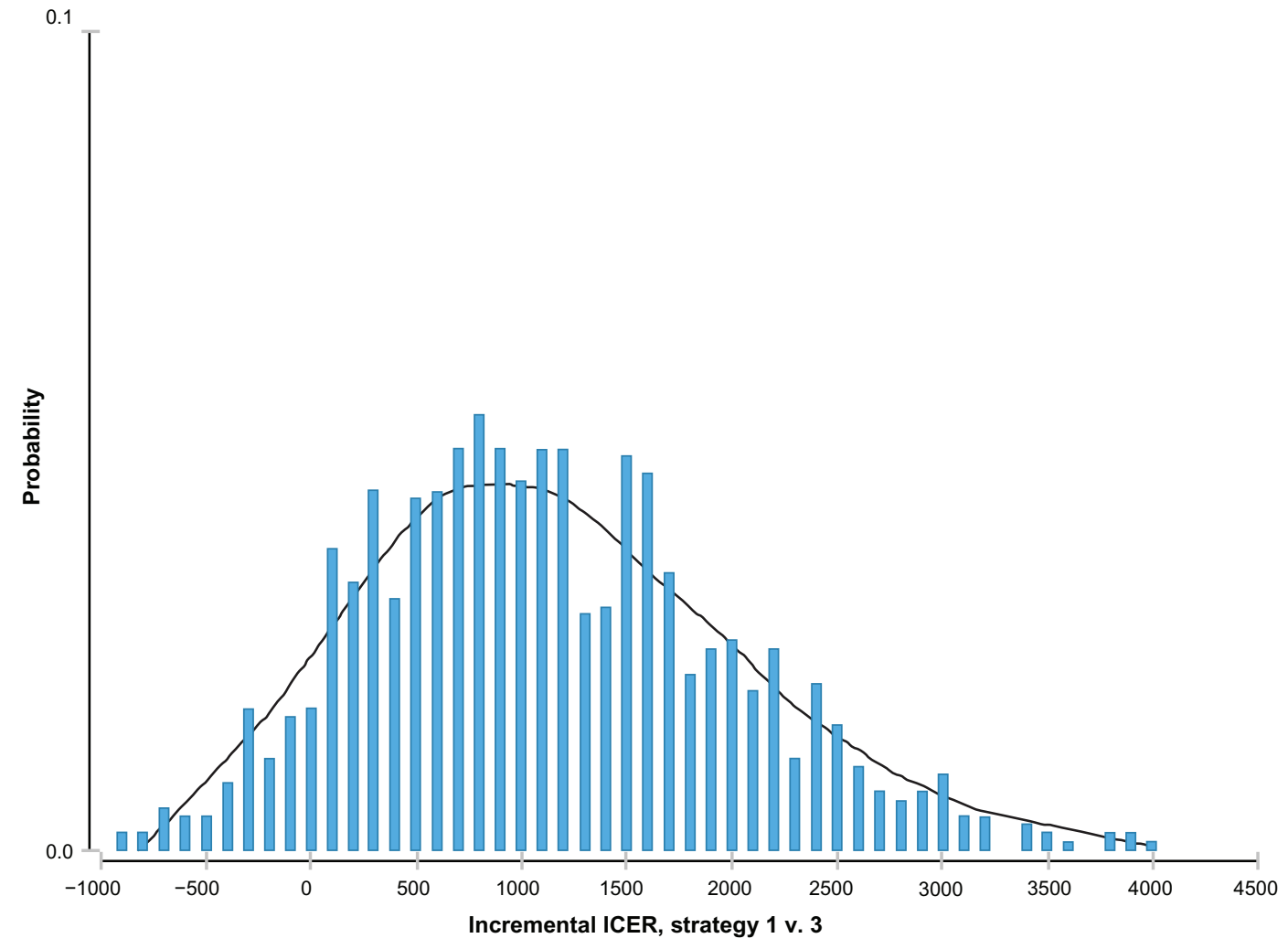

Figure 4 Incremental cost effectiveness ratio (ICER) distribution probability of escitalopram versus paroxetine. Note: Mean I I22.9; standard deviation 866.6. 


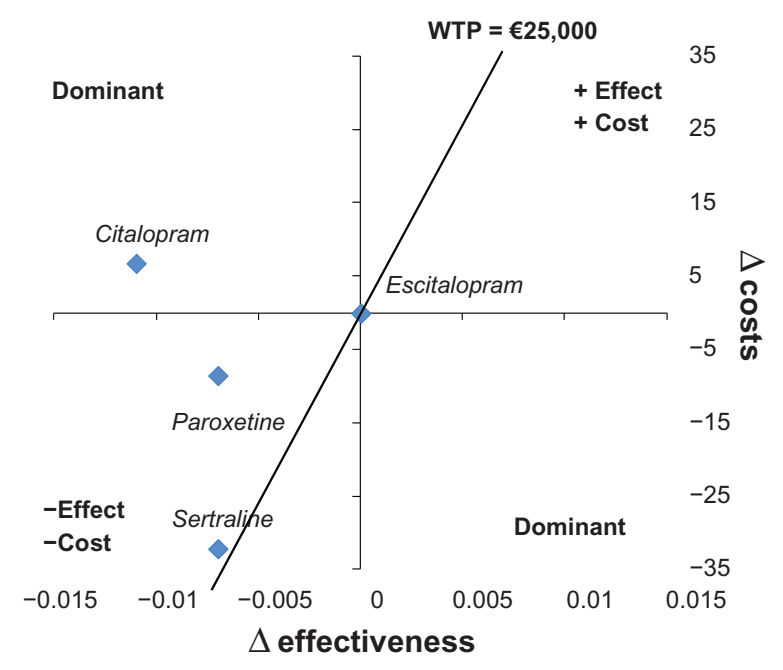

Figure 5 Cost-effectiveness analysis plan.

Abbreviation: WTP, willingness to pay.

disorder, escitalopram was dominant over citalopram in most of the one-way sensitive analyses. Escitalopram yielded ICERs with a maximum value of about $€ 9800$ compared with paroxetine, and ICERs ranging from about $€ 115$ to about $€ 18,000$ compared with sertraline. The high variability in the ICER for the comparison of escitalopram versus sertraline is due to the remission rate that, being the only parameter specific for each drug, was very sensitive to small variations. Despite the wide range of ICER values, Monte Carlo simulation showed that ICER values for escitalopram were centered around $€ 1100$ compared with paroxetine and around $€ 4400$ compared with sertraline. CEAC confirmed these results, with an ICER break-even point of around $€ 1000$ for escitalopram versus paroxetine and $€ 5000$ for escitalopram versus sertraline. Although there is no official cost-effectiveness threshold in Italy, the

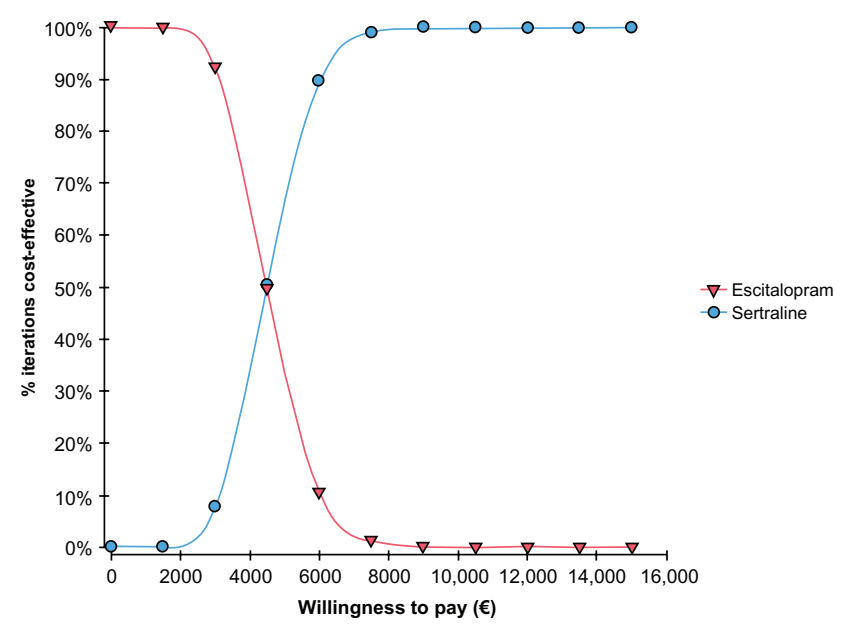

Figure 6 Cost-effectiveness acceptability curve for escitalopram versus sertraline.

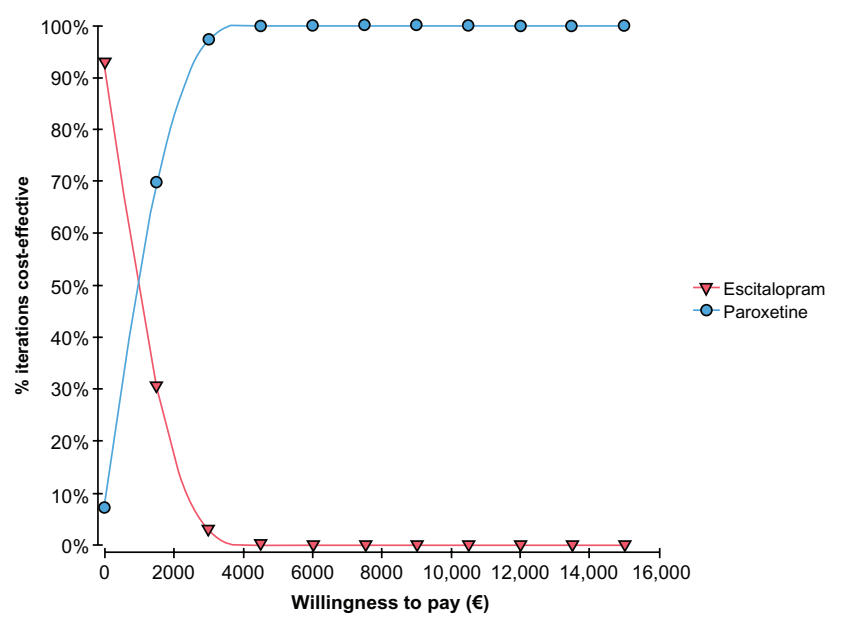

Figure 7 Cost-effectiveness acceptability curve for escitalopram versus paroxetine.

value of $€ 25,000$ could be suggested as being acceptable also for Italy. All values of ICERs retrieved in all analyses were lower than this threshold.

In the TLV model, escitalopram was dominant versus the other molecules except for mirtazapine when using all studies in the meta-analysis to calculate remission frequencies. The cost and effect ratio for escitalopram compared with mirtazapine was approximately 61,000 Swedish crowns (about $€ 7000$ ). Considering only studies with a follow-up period of $8-12$ weeks, the results changed and escitalopram became dominant over all alternatives, including mirtazapine.

A review by Cipriani et al showed the superior clinical efficacy of escitalopram versus citalopram, sertraline, and paroxetine. ${ }^{33}$ In a study that compared direct costs and the cost-effectiveness of eight SSRIs in the US, escitalopram was the least expensive and the most cost-effective drug, and adverse reactions were considered in this study for

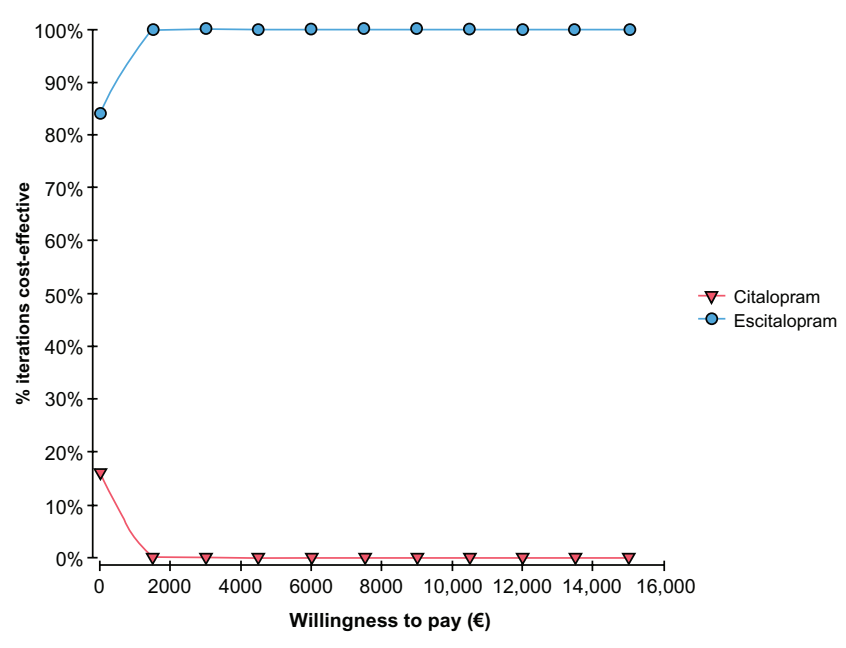

Figure 8 Cost-effectiveness acceptability curve for escitalopram versus citalopram. 
calculation of direct costs that were applied to the model having a significant impact on the success of escitalopram because of lower incidence. ${ }^{34}$

As with any pharmacoeconomic modeling, this study has some limitations. For example, bias may be present because of using data from different sources. In our case, the probability of remission, relapse, and attempted suicide came from a meta-analysis and two randomized controlled trials, respectively. The lack of data from observational studies is an important limitation to a pharmacoeconomic study because analyses based mostly on randomized controlled trials provide values that are far from "real life". Another potential limitation of our study is that the main clinical inputs for the model were based on studies not performed in an Italian health care setting, but the probabilities of clinical events are not usually considered country-specific. ${ }^{35}$ Another important limitation due to the lack of published local data was that data on resource utilization, treatment patterns, and some utilities were based on estimates from an expert panel. However, it has been suggested that use of expert opinion is appropriate for situations in which there is little or no published material in a particular area, or in which the findings from a thorough literature review are considered unreliable, conflicting, or insufficient to cover the requirements of a study. ${ }^{36}$

\section{Conclusion}

The findings from this cost-effectiveness analysis indicate that escitalopram could be accepted as a cost-effectiveness strategy for the Lombardy region health service compared with citalopram, sertraline, and paroxetine in the first-line treatment of major depressive disorder. This assessment is based on ICERs resulting from this analysis, which are lower than the threshold proposed by several agencies in other countries. These benefits are driven by the effectiveness of escitalopram, resulting in improved health-related quality of life and probability of sustained remission and health care resource utilization. The findings from the sensitivity analyses in this study support the robustness of the model. The results of this analysis are in line with the TLV model.

\section{Author contributions}

Dr Katz and Dr Ripellino were responsible for model development and writing of the manuscript. Professor Mencacci and Dr Di Sciascio were responsible for clinical validation of the model and review of the manuscript. All authors read and approved the final manuscript.

\section{Acknowledgments}

The authors wish to thank Dr Radice for quality assurance of the model and review of the manuscript and Dr Percudani for clinical validation of the model and review of the manuscript.

\section{Disclosure}

This study was financially supported by an unrestricted grant from Lundbeck Italy SpA which was not responsible for creation of the study protocol, the data analysis, data interpretation, or writing of the manuscript. CM, GDS, and Drs Percudani and Radice have received honoraria from CSD Medical Research SrL. PK and CR are employees of CSD Medical Research SrL. The authors report no other conflicts of interest in this work.

\section{References}

1. Croom K, Plosker G. Spotlight on the pharmacoeconomics of escitalopram in depression. CNS Drugs. 2004;18:469-473.

2. Moore JD, Bona JR. Depression and dysthymia. Med Clin North Am. 2001;85:631-644

3. Girolamo G, Polidori G, Morosini P, et al. Prevalence of common mental disorders in Italy: results from the European Study of the Epidemiology of Mental Disorders (ESEMeD) project. Acta Psychiatr Scand Suppl. 2004;420:21-27.

4. Colombo G, Di Matteo S. Nel Trattamento della Depressione Maggiore Nelle Diverse Regioni Italiane: Il Ruolo di Venlafaxina [Budget Impact Analysis in the Treatment of Major Depressive Disorder on Italian Regions: The Role of Venlafaxine]. Milan: W.H.E.RE. Medical Press Srl; 2009. Italian.

5. Battaglia A, Dubini A, Mannheimer R, Pancheri P. Depression in the Italian community: epidemiology and socio-economic implications. Int Clin Psychopharmacol. 2004;19:135-142.

6. Greenberg PE, Kessler RC, Birnbaum HG, et al. The economic burden of depression in the United States: how did it change between 1990 and 2000? J Clin Psychiatry. 2003;64:1465-1475.

7. Stoudemire A, Frank R, Hedemark N, Kamlet M, Blazer D. The economic burden of depression. Gen Hosp Psychiatry. 1986;8:387-394.

8. Kind P, Sorensen J. The costs of depression. Int Clin Psychopharmacol. 1993;7:191-195.

9. Frank L, Revicki DA, Sorensen SV, et al. The economics of selective serotonin reuptake inhibitors in depression: a critical review. CNS Drugs. 2001;15:59-83.

10. Panzarino PJ, Nash DB. Cost-effective treatment of depression with selective serotonin reuptake inhibitors. Am J Manag Care. 2001;7: 173-184.

11. Revicki DA, Simon GE, Chan K, et al. Depression, health-related quality of life, and medical cost outcomes of receiving recommended levels of antidepressant treatment. J Fam Pract. 1998;47:446-452.

12. Ellis P. Australian and New Zealand clinical practice guidelines for the treatment of depression. Aust N Z J Psychiatry. 2004;38:389-407.

13. National Guideline Clearinghouse: Depression. The treatment and management of depression in adults [webpage on the Internet]. Guideline summary. London, UK: National Institute for Health and Clinical Excellence; 2009. Available from: http://guideline.gov/content. aspx?id=15521. Accessed December 17, 2012.

14. Cipriani A, Furukawa TA, Salanti G, et al. Comparative efficacy and acceptability of 12 new-generation antidepressants: a multipletreatments meta-analysis. Lancet. 2009;373:746-758.

15. Trifirò G, Tillati S, Spina E, et al. A nationwide prospective study on prescribing pattern of antidepressant drugs in Italian primary care. Eur J Clin Pharmacol. Epub June 17, 2012. 
16. Wessling A, Ramsberg J. Depression: The Review of Antidepressants. Solna, Sweden: The Dental and Pharmaceutical Benefits Agency; 2008. Available from: http://www.tlv.se/Upload/genomgangen/reviewantidepressants.pdf. Accessed November 21, 2012.

17. Gaynes B, Rush A, Madhukar T, Wisniewski S, Spencer D, Fava M. The STAR*D study: treating depression in the real world. Cleve Clin J Med.2008;75:57-66.

18. Gilchrist G, Gunn J. Observational studies of depression in primary care: what do we know? BMC Fam Pract. 2007;8:28.

19. Lothgren M, Hemels M, Francois C, Joensson BA. Cost-effectiveness analysis of escitalopram as first line treatment of depression in Sweden. Primary Care Psychiatry. 2004;9:153-162.

20. Khan A, Khan SR, Leventhal RM, Brown WA. Symptom reduction and suicide risk in patients treated with placebo in antidepressant clinical trials: a replication analysis of the Food and Drug Administration Database. Int J Neuropsychopharmacol. 2001;4:113-118.

21. Agenzia Italiana del Farmaco [homepage on the Internet]. Rome: Agenzia Italiana del Farmaco. Available from: http://www.agenziafarmaco.gov. it/. Accessed November 21, 2012.

22. WHOCC [homepage on the Internet]. International language for drug utilization research. Oslo, Norway: World Health Organization Collaborating Center for Drug Statistics Methodology; updated May 4, 2012 Available from: http://www.whocc.no/. Accessed November 21, 2012.

23. Sobocki P, Ekman M, Agren H, Runeson B, Jönsson B. The mission is remission: health economic consequences of achieving full remission with antidepressant treatment for depression. Int J Clin Pract. 2006;60: 791-798.

24. Peveler R, Kendrick T, Buxton M, et al. A randomised controlled trial to compare the cost-effectiveness of tricyclic antidepressants, selective serotonin reuptake inhibitors and lofepramine. Health Technol Assess. 2005;9:1-134, iii.

25. Jamison DT, Breman JG, Measham AR, et al, editors. Cost-effectiveness analysis. In: Priorities in Health. Washington, DC: World Bank; 2006. Available from: http://www.ncbi.nlm.nih.gov/books/NBK10253/. Accessed November 21, 2012.

26. Lucioni C, Ravasio R. Come valutare i risultati di uno studio farmacoeconomico? How to evaluate the results of a pharmacoeconomic analysis? PharmacoEconomics - Italian Research Articles. 2004;3 121-130. Italian.
27. Capri S, Ricciardi W. Advate nel trattamento dell'emofilia A - analisi costo-efficacia della terapia on-demand versus profilassi basata sull'emivita del prodotto. [Advate in the treatment of emofilia A cost-effectiveness of an on-demand therapy versus a prophylaxis based on the half-life of the product]. Ital J Public Health. 2011;8:61-67. Italian.

28. UK's NICE unlikely to bow to new pricing suggestions. Financial Times. May 10, 2012.

29. Rawlins MD, Culyer AJ. National Institute for Clinical Excellence and its value judgements. BMJ. 2004;329:224-227.

30. Culyer AJ. Introduction. In: Towse A, Pritchard C, Devlin N, editors. Cost Effectiveness Thresholds: Economic and Ethical Issues. London, UK: Kings Fund and Office of Health Economics; 2002.

31. Palisade Corporation: Maker of Risk and Decision Analysis Software using Monte Carlo Simulation [homepage on the Internet]. Ithaca, NY: Palisade Corporation; 2012. Available from: http:/www.palisade.com/. Accessed November 21, 2012.

32. CEA Registry [homepage on the Internet]. Boston, MA: CostEffectiveness Analysis Registry. Available from: https://research. tufts-nemc.org/cear4/. Accessed November 21, 2012.

33. Cipriani A, Santilli C, Furukawa TA, et al. Escitalopram versus other antidepressive agents for depression. Cochrane Database Syst Rev. 2009;2:CD006532.

34. Sullivan PW, Valuck R, Saseen J, MacFall HM. A comparison of the direct costs and cost effectiveness of serotonin reuptake inhibitors and associated adverse drug reactions. CNS Drugs. 2004;18:911-932.

35. Nuijten M, Brignone M, Marteau F, den Boer J, Hoencamp E. Costeffectiveness of escitalopram in major depressive disorder in the Dutch health care. Clin Ther. 2012;34:1364-1378.

36. Evans C. The use of consensus methods and expert panels in pharmacoeconomic studies: practical applications and methodological shortcomings. Pharmacoeconomics. 1997;12:121-129.

37. Nelson JC, Papakostas GI. Atypical antipsychotic augmentation in major depressive disorder: a meta-analysis of placebo-controlled randomized trials. Am J Psychiatry. 2009;166:980-991.

38. Garattini L, Castelnuovo E, Lanzeni D, et al. Durata e Costo delle visite in medicina generale. Il progetto DYSCO [Duration and cost of general practitioner visits. The DYSCO project]. Farmeconomia. Health Economics and Therapeutic Pathways. 2003;4:109-114. Italian.
ClinicoEconomics and Outcomes Research

\section{Publish your work in this journal}

ClinicoEconomics \& Outcomes Research is an international, peerreviewed open-access journal focusing on Health Technology Assessment, Pharmacoeconomics and Outcomes Research in the areas of diagnosis, medical devices, and clinical, surgical and pharmacological intervention. The economic impact of health policy and health systems

\section{Dovepress}

organization also constitute important areas of coverage. The manuscript management system is completely online and includes a very quick and fair peer-review system, which is all easy to use. Visit http://www.dovepress.com/testimonials.php to read real quotes from published authors. 